\title{
Electrochemical bath deposition technique: Deposition of CdS thin films
}

\author{
S H PAWAR, C H BHOSALE and L P DESHMUKH \\ Department of Physics, Shivaji University, Kolhapur 416004, India
}

\begin{abstract}
Cadmium sulphide thin films have been deposited onto chromium plated stainless steel substrates under the influence of electric field. The various deposition parameters such as speed of rotation of the substrates, temperature of the chemical bath, molar concentrations of solution and the strength of the electric field were kept at optimized conditions. The electrochemical photovoltaic (ECPV) cells are formed with CdS film electrodes. The properties of CdS films and ECPV cells are monitored with selective values of the electric field employed in the controlled precipitation technique. This relatively new technique is described and the possible film formation mechanism suggested.
\end{abstract}

Keywords. Anodic chemical film; cathodic chemical film; electrochemical photovoltaic cells.

\section{Introduction}

Recent investigations have developed considerable interest in CdS thin film due to its intermediate band gap, high absorption coefficient and considerable energy conversion efficiency. This resulted from the discovery of Ellis et al (1976) that photodecomposition of $\mathrm{CdS}$ can be quenched by adding polysulphides to the aqueous solution. Much work has been done on the $\mathrm{CdS}$ thin films and their use in electrochemical photovoltaic (ECPV) cells. Various preparative and post-preparative treatments have been given to CdS photoanode (Lokhande et al 1983; Mukherjee and Das 1980) to improve the performance and efficiency of these cells.

In this investigation an attempt has been made to improve the ouput current and voltage of the ECPV cell formed with CdS photoanode, prepared under the influence of an electric field. This paper also presents the formation mechanism of CdS film prepared anodically and cathodically.

\section{Experimental}

The reaction mixture was prepared as under: 20 c.c. of desired molar $\mathrm{CdSO}_{4}$ solution was taken in 250 c.c. beaker and an appropriate amount of $14 \mathrm{M}$ liquor ammonia was slowly added into it at room temperature, with continuous stirring, to redissolve the white precipitate of $\mathrm{Cd}(\mathrm{OH})_{2}$. The $\mathrm{pH}$ of the deposition mixture was adjusted to 10 . The mixture was then diluted to a total volume of 120 c.c. by adding double-distilled water. This reaction vessel containing the turbid solution of $\mathrm{Cd}(\mathrm{OH})_{2}$ was kept in an oil bath maintained at $90^{\circ} \mathrm{C}$. The ultrasonically-cleaned chromium-plated stainless-steel substrates fixed in a specially designed substrate holder were rotated by 75 r.p.m. a.c. motor, in a reaction vessel for $30 \mathrm{~min}$ at $85^{\circ} \mathrm{C}$. The desired molar thiourea solution was added into the reaction vessel at the rate of $0.7 \mathrm{ml} / \mathrm{min}$. Before adding thiourea an 
electric field of proper magnitude was applied between chromium plated stainless steel substrates and a ring-shaped stainless steel electrode, the distance between the electrode and the substrate being $1 \mathrm{~cm}$. The CdS film was deposited onto the chromium-plated stainless steel substrates first with positive bias (by applying positive potential to the substrates), and then cathodically (by applying negative potential to the substrates) by applying d.c. $900 \mathrm{mV}$ voltage. The current maintained during the deposition was $0.15 \mathrm{~mA}$. The films so deposited were taken out of the reaction vessel, washed several times with double-distilled water, dried and then heated in a furnace for an hour at $200^{\circ} \mathrm{C}$. The photoanode area was defined by the coal tar.

The ECPV cell was formed simply by immersing the photoanode and the counter electrode in an electrolyte. Platinum was used as a counter electrode in the cell and the properties of the films were investigated.

\section{Results and discussion}

The method of formation of thin films by controlled precipitation technique, also called chemical bath deposition technique, was modified by employing additional electric fields between conducting substrates and the counter electrode made up of chemically inert metallic cylinder. The chemical mixture was stirred in to the electric cylindrical cell. The CdS films were formed by sustaining the conducting substrates both at positive and negative potentials, known as anodic and cathodic chemical films respectively.

A systematic investigation was made to reveal the role of the preparative parameters such as speed of rotation of substrates, temperature of the electrochemical bath, $\mathrm{pH}$ of the solution, strength of electric field etc on the properties of the films. It was found that, at low speeds of substrates $(50-60 \mathrm{rpm})$, films were thick, nonspecular, and nonuniform. At higher speed (150 rpm), films were thin, specular and adhesive, while at intermediate speeds $(70-80 \mathrm{rpm})$, films were smooth, specularly reflecting, adhesive and uniform. The films formed on the stationary substrates were porous, powdery, thick and nonuniform. Rotation of substrates in to the electric cylindrical cell may help to increase the deposition of $\mathrm{CdS}$ molecules on the substrates, affecting the quality of the film.

The dissociation of complex and anion compounds depends on the temperature of the electrochemical bath. The optimum temperature of the electrochemical bath, for the growth of $\mathrm{CdS}$ films, was determined as $85 \pm 5^{\circ} \mathrm{C}$. Similarly the concentrations of the chemical ingredients used, the strength of the electric field and the $\mathrm{pH}$ of the mixture were optimized.

In chemical bath deposition technique, Kaur et al (1980) suggested the growth mechanism for CdS film formation, according to which, film formation takes place either by ion-by-ion condensation of $\mathrm{Cd}^{2+}$ and $\mathrm{S}^{2-}$ ions or by adsorption of colloidal $\mathrm{CdS}$ particles formed in the reaction mixture. Formation of $\mathrm{CdS}$ nuclei by combination of ions on the substrate surface requires some catalytic solid phase on the substrate surface, which can preferentially adsorb $\mathrm{Cd}^{2+}$ or $\mathrm{S}^{2-}$ ions to form $\mathrm{CdS}$.

In our electrochemical bath deposition technique, the above mechanism was modified by applying electric field. The CdS molecules thus formed are in dispersed state due to the stirring of the chemical mixture. Generally the dispersed CdS and CdSe molecules exhibit negative charges. These negatively-charged particles under the influence of electric field are bound to attract or repel from the electrically-energized substrate electrode, depending on its polarity. The influence of the electric field on the 
growth mechanism of CdS and CdSe films was earlier studied by Ueno et al (1983) in electrophoretic technique. In the present investigation, chromium-plated stainless steel substrate dipped in a suspension of $\mathrm{Cd}(\mathrm{OH})_{2}$ has a layer of $\mathrm{Cd}(\mathrm{OH})_{2}$ on it, which acts as a catalytic solid phase, to stimulate the decomposition of thiourea. Decomposition of thiourea in the deposition mixture supplies $S^{2-}$ ions which then combine with $\mathrm{Cd}(\mathrm{OH})_{2}$ to form $\mathrm{CdS}$ molecule. It is therefore quite obvious that, if positive potential is given to the conducting substrates, these negatively-charged CdS molecules attract towards the substrates and get deposited on the substrates. Thus the growth of CdS thin film takes place molecule-by-molecule. The rate of deposition of CdS molecules on the substrate surface is increased due to the application of electric field with substrates at the positive potential. Stirring of the solution under the influence of electric field increases the rate of deposition of CdS molecules on the substrates.

For cathodic chemical CdS films, the rate of deposition of $\mathrm{CdS}$ molecules onto the substrate surface is decreased. This automatically decreases the deposition rate of $\mathrm{CdS}$ molecules on the substrate surface, but at the same time the deposition rate of CdS molecules on the ring shaped metallic counter electrode is increased as it is at the positive potential. It is thus clear that the anodic films are more adherent, physically coherent and smoother than the latter.

The properties of CdS films were studied by the method of semiconductorelectrolyte junction. In the present investigation, ECPv cells, termed as $\mathrm{Cr} / \mathrm{CdS}-\mathrm{NaOH}$ $\mathrm{Na}_{2} \mathrm{~S}-\mathrm{S} / \mathrm{Pt}$, were fabricated with both anodic and cathodic chemical CdS films. The current-voltage $(\mathrm{I}-\mathrm{V})$ characteristics, both in dark and light for anodic and cathodic

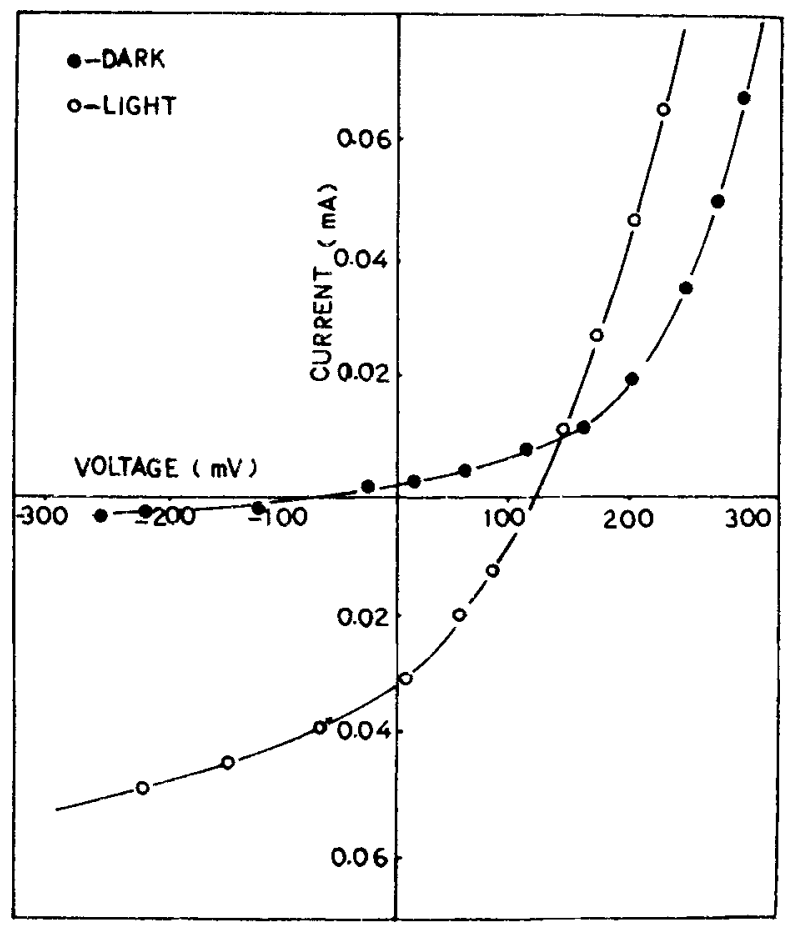

Figure 1. Current-voltage characteristics in the dark and light for the ECPV cell formed with anodic chemical CdS film. 


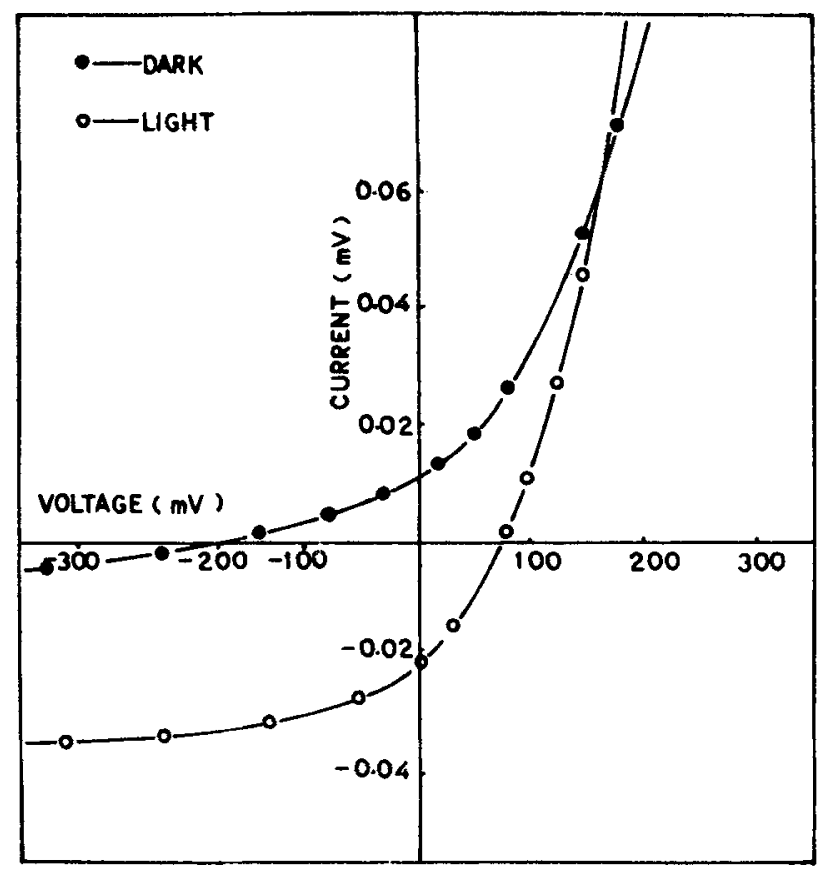

Figure 2. Current-voltage characteristics in the dark and light for the ECPV cell formed with cathodic chemical CdS film.

chemical CdS films are, shown in figures 1 and 2 respectively. It is seen that the photovoltaic output performance for the ECPV cell formed with anodic chemical CdS films is better than that formed with the cathodic chemical CdS film. This is attributed to the superiority of the anodic chemical CdS film.

\section{Acknowledgements}

The authors are grateful to the University Grants Commission, New Delhi for financial support. One of the authors (CHB) is indebted to Rayat Shikshan Sanstha, Satara for granting study leave.

\section{References}

Ellis A B, Kaiser S W and Wrighton M S $1976 \mathrm{~J}$. Am. Chem. Soc. 981635

Kaur I, Pandya D K and Chopra K L 1980 J. Electrochem. Soc. 127943

Lokhande C D, Uplane M D and Pawar S H 1983 Indian J. Pure Appl. Phys. 2178

Mukherjee M K and Das S K 1980 Proc. National Solar Energy Conversion (Madras: Allied Publishers) 326

Ueno Y, Minoura H, Nishikawa T and Masayasu T 1983 J. Electrochem. Soc. 13043 